\title{
Is the Design of Bonus-Malus Systems Influenced by Insurance Maturity or National Culture?-Evidence from Asia
}

\author{
Sojung C. Park ${ }^{\mathrm{a}}$, Jean Lemaire ${ }^{\mathrm{b}}$ and Choong Tze Chua ${ }^{\mathrm{c}}$ \\ ${ }^{a}$ Department of Finance, Mihaylo College of Business and Economics, California State University, \\ P.O. Box 6848 Fullerton, CA 92834-6848, U.S.A. \\ E-mail: sopark@fullerton.edu \\ ${ }^{\mathrm{b}}$ Department of Insurance \& Risk Management, Wharton School, University of Pennsylvania, 3620 Locust \\ Walk, 3404 Steinberg Hall-Dietrich Hall, Philadelphia, PA 19104-6218, U.S.A. \\ E-mail: lemaire@wharton.upenn.edu \\ ${ }^{c}$ Lee Kong Chian School of Business, Singapore Management University, 50 Stamford Road, \#04-045, \\ 178899 Singapore. \\ E-mail: ctchua@smu.edu.sg
}

Most Asian countries have adopted bonus-malus systems (BMS) in automobile insurance. We evaluate the toughness towards consumers of 16 Asian BMS and its correlation with cultural and economic variables. We use principal components analysis to define a Maturity Index of insurance markets and find supporting evidence for a conjecture that, as markets become more mature and policy-holders more sophisticated, countries adopt tougher BMS. In addition, we find, using regression analysis, that using a Common Law legal system is a crucial factor in BMS design. Cultural variables, such as uncertainty avoidance, also influence BMS. The Geneva Papers (2010) 35, S7-S27. doi:10.1057/gpp.2010.37;

published online 1 December 2010

Keywords: bonus-malus system; cultural impact; insurance market maturity

\section{Background}

Lemaire and $\mathrm{Zi}^{1}$ analysed 30 bonus-malus systems (BMS) from all over the world and used principal components analysis to create an Index of Toughness of BMS. They concluded that the following two conjectures were valid for their sample:

(1) Conjecture \#1: The design of a BMS is influenced by economic development. More advanced countries tend to enforce tougher BMS. As insurance markets become more mature and policy-holders become more sophisticated, countries switch to more severe BMS. BMS in developing countries are often embryonic, with just a few classes and very simple transition rules.

(2) Conjecture \#2: Culture also seems to influence BMS design, as countries with similar GDP per capita may adopt very different BMS. Strong geographical patterns emerge from the ranking of BMS. Countries from Northern and Central Europe use the toughest BMS. Asian countries for the most part adopt fairly mild BMS.

\footnotetext{
${ }^{1}$ Lemaire and Zi (1994).
} 
In this article we revisit these two conjectures, with particular emphasis on East and South Asia. This region of the world is of much interest, as it includes countries with strong and mature insurance markets (Japan, Singapore), markets expanding at a rapid pace (China, India), as well as emerging markets (Malaysia, Sri Lanka). Also, Asia is the only continent where national BMS are enforced in all countries. In other continents, individual insurers are able to devise their own BMS in several countries. The BMS and insurance markets of the following 16 Asian countries are analysed: Bangladesh, China, Hong Kong, India, Indonesia, Japan, Kazakhstan, South Korea, Malaysia, Pakistan, Philippines, Singapore, Sri Lanka, Taiwan, Thailand and Vietnam. Principal components analysis and regression models are built to explain the toughness of BMS by means of a set of economic and cultural variables to check whether, as conjectured by Lemaire and $\mathrm{Zi}$, the design of BMS is related to the degree of maturity of markets and national culture. In several countries (Philippines, Kazakhstan) insurers are considering implementing a BMS. In other countries (India, China) changes to the existing BMS are contemplated. Results should help practitioners involved in BMS design to develop systems that correspond to their country's level of development and cultural approach to insurance.

\section{The coefficient of variation (CV) as measure of toughness of BMS}

BMS need to have simple transition rules, easily understood by policy-holders. Certificates issued in case of an insurance company switch also need to be easy to establish: they should not require the current insurer to collect the entire claims history of the policy-holder. This explains why all BMS in force around the world can be characterised as discrete Markov Chains. The first published treatment of BMS through Markov Chain theory is due to Franckx. ${ }^{2}$ A large set of references on the Markov Chain analysis of BMS can be found in Lemaire. ${ }^{3}$

BMS can be studied from the insurer's or the policy-holder's perspective. Mixed Poisson distributions have traditionally been used to model the insurer's claim count probabilities; mixing distributions that have been proposed include the Gamma, ${ }^{4} \mathrm{a}$ two-point discrete distribution, ${ }^{5}$ the Inverse Gaussian, Beta, Uniform, Pareto ${ }^{6}$ and the Weibull, Bessel, $\chi^{2}$ and truncated Normal. ${ }^{7}$ The Poisson distribution has been used exclusively to model individual policy-holder's claim counts; it is used in this research.

Dozens of observed claim number distributions have been presented in the actuarial literature. Articles that compare the goodness-of-fit of different models using several observed distributions include Denuit ${ }^{8}$ and Gossiaux and Lemaire. ${ }^{9}$ For claims

\footnotetext{
${ }^{2}$ Franckx (1960).

${ }^{3}$ Lemaire (2004).

${ }^{4}$ Bichsel (1960).

${ }^{5}$ Derron (1963).

${ }^{6}$ Willmot (1986).

${ }^{7}$ Albrecht (1982).

${ }^{8}$ Denuit (1997).

${ }^{9}$ Gossiaux and Lemaire (1981).
} 
distributions pre-dating the first 1974 oil shock, observed means range between 0.10 and 0.20 . More recent distributions exhibit observed means between 0.07 and 0.12 , averaging 0.10 . Therefore, in this article, we assume that the number of claims of each policy-holder follows a Poisson distribution with mean 0.10.

We evaluate the toughness of BMS by the CV of a policy-holder's BMS premium, once the Markov Chain has reached stationary state. The CV, sometimes also called the Unitized Risk, is a normalised measure of risk, defined as the standard deviation (STD) divided by the mean of a random variable. Insurance researchers commonly use this measure to compare risk across lines of business. For instance, Bühlmann and Gisler ${ }^{10}$ find that claim size CVs for various lines range between 2.0 for household and motor hull insurance to 9.0 for motor liability and Workers' Compensation (in case of accident) insurance. $\mathrm{AON}^{11}$ quantifies the systemic risk or volatility associated with each line of business for 17 countries comprising over 75 per cent of the world's global premium. Risk is defined as the CV of the loss ratio of each book of business. CVs range between 0.14 for private passenger auto insurance to 3.51 for financial guaranty insurance.

The $\mathrm{CV}$ is an appropriate measure to evaluate the toughness of BMS. It is a dimension-less parameter, suitable for international comparisons as it is independent of currency conversions. Without any form of BMS or experience rating, the variability of the annual premiums paid by a given policy-holder is zero (perfect solidarity). Without any kind of insurance, drivers need to pay all claims out-of-pocket, and the variability of payments, the variability of the claims process, attains its maximum value (no solidarity). A BMS represents an intermediate situation, as annual premiums become a random variable and personalised premiums vary according to claims history. The CV of the stationary annual premium consequently measures solidarity across policyholders: the tougher the BMS, the higher the CV.

More importantly, the CV was found to be the best measure of toughness in Lemaire and $\mathrm{Zi}^{1}{ }^{1}$ In that study the authors introduced four measures of toughness, summarised in an Index of Toughness using principal components analysis. The CV was found to be by far the best single measure of toughness, with a correlation of 0.97 with the composite Index of Toughness.

The BMS in force (as of June 2008) in all 16 Asian countries are summarised in Appendix B. Table 1 ranks these countries according to CV. Note that Kazakhstan and the Philippines do not currently use a BMS.

This ranking is certainly surprising. Few would expect that Bangladesh and Sri Lanka, two of the poorest countries in our database, would adopt the toughest BMS in Asia. Bangladesh and Sri Lanka both have very severe penalties in case of a single claim. In Bangladesh, the transition rules of the BMS send any policy-holder with one claim to premium level 130, irrespectively of the current class; the premium level from a best-class driver will increase from 50 to 130 , a 160 per cent increase, after just one claim. Sri Lankan transition rules are hardly more lenient: drivers from the bottom three classes, at premium levels 30, 35 and 40, move up three classes after one claim. Drivers in all other bonus classes, at premium levels 45-95, lose their entire

\footnotetext{
${ }^{10}$ Bühlmann and Gisler (2005).

11 AON (2008).
} 
$\mathrm{S} 10$

Table 1 CV for all 16 Asian countries

\begin{tabular}{lr}
\hline Country & $C V$ \\
\hline Bangladesh & 0.5053 \\
Sri Lanka & 0.4041 \\
Malaysia & 0.3092 \\
Hong Kong & 0.2950 \\
Taiwan & 0.2805 \\
Singapore & 0.2298 \\
Korea & 0.2032 \\
India & 0.1480 \\
China & 0.1322 \\
Japan & 0.0831 \\
Indonesia & 0.0824 \\
Pakistan & 0.0808 \\
Thailand & 0.0779 \\
Vietnam & 0.0748 \\
Kazakhstan & 0.0000 \\
Philippines & 0.0000
\end{tabular}

accumulated bonus after one claim and are sent back to the starting class, at level 100 . This initial result appears to contradict Lemaire and Zi's conjecture \#1, that tougher BMS are found in the most developed countries, but we explore further statistical studies, based on principal components and regression analyses.

\section{Factors influencing the toughness of BMS}

According to Lemaire and $\mathrm{Zi}$, BMS design is linked to insurance "maturity", an abstract, qualitative concept, that we approach by defining several variables that are intuitively related. Insurance markets are probably more mature in richer countries, in countries where a large fraction of the GDP is devoted to insurance, in countries where a large number of companies compete. Sophisticated BMS are in force in countries with developed insurance markets; development can be slowed by political, financial and economic risk: nations with little risk are more attractive to foreign investment. Also, it is likely that some cultures are more prone to the development of insurance than others; in some countries, there are alternative ways than insurance to reduce life's uncertainties, for instance, a developed family kin system. ${ }^{12}$ This leads to the definition of several variables that are probably correlated with the maturity of insurance markets - hence to the severity of BMS. The study uses 2005 data, the latest available for some variables.

The non-life insurance density, at Purchasing Power Parity (PPP)

In its annual study of world insurance markets, the Swiss Reinsurance Company ${ }^{13}$ ranks 88 countries according to Non-Life Insurance Density, defined as the premium

\footnotetext{
${ }^{12}$ Chui and Kwok (2008).

${ }^{13}$ Swiss Reinsurance Company (2006).
} 
per capita, in U.S. dollars. To better reflect differences in purchasing power, a PPP correction has been applied to the non-life insurance premium density. Premiums per capita can be converted to U.S. dollars either using market currency exchange rates, or at PPP. The use of market rates can lead to misleading conclusions when comparing per-capita living conditions across countries. Economists prefer to correct the data by a PPP factor that attempts to reflect the differences in prices and services between a country and the United States. The PPP correction can be significant; for instance, the uncorrected Gross Domestic Product (GDP) per capita in China translates, at the official exchange rate, to US\$1,708. A PPP correction factor of 3.9816 increases the GDP to US\$6,800, a better indication of standards of living in China. (Source: CIA World Factbook, www.cia.gov)

\section{The non-life insurance penetration}

This measure also comes from the Swiss Reinsurance Company annual study: non-life insurance premiums, as a percentage of GDP.

\section{Market concentration}

A mature insurance market is expected to have many insurers freely competing for customers, thus a low market concentration. We measure concentration with a modified Herfindahl Index, defined as the sum of the squared market shares of the ten largest non-life insurers (Source: Axco Insurance Markets Report ${ }^{14}$ and International Fact Book: www.internationalinsurance.org/international/toc/).

\section{The number of actuaries per 100,000 inhabitants}

A large number of actuaries in a country is indicative of insurance sophistication and development. In addition, actuaries are instrumental to the design of BMS (Source: International Actuarial Association, www.actuaries.org, for number of actuaries and U.S. Census Bureau, www.census.gov/ipc/www/idb/ranks.html, for population data).

\section{The GDP per capita, at PPP}

More affluent countries, as measured by GDP per capita at PPP, are likely to have more mature insurance market (Source: CIA World Factbook, www.cia.gov).

\section{The political risk index}

Nations where there is little political and investment risk are more likely to have mature insurance markets, as the financial environment is more conducive to foreign investment, and financial contracts such as insurance policies are easier to enforce. The Political Risk Services Group publishes an International Country Risk Guide, rating

\footnotetext{
${ }^{14}$ Axco Insurance Markets Report (2007).
} 
most nations around the world according to political, financial and economic risk. The Political Risk Index (that could also be called the Risk Index for International Business) is the outcome of a statistical risk model that analyses the potential risks of international business operations. Countries receive scores on 12 risk components:

- Government stability (government unity, legislative strength, popular support);

- Socioeconomic conditions (unemployment, consumer confidence, poverty);

- Investment profile (contract viability, expropriation risk, profit repatriation, payment delays);

- Internal conflict (civil war threat, political violence, civil disorder);

- External conflict (war, cross-border conflict, foreign pressures);

- Corruption;

- Military in politics;

- Religious tensions;

- Law and order (strength and impartiality of judicial system, popular observance of the law);

- Ethnic tensions;

- Democratic accountability;

- Bureaucratic quality.

Total scores range between 0 and 100, with 100 representing a very low degree of political risk (Source: www.prsgroup.com).

Not only the maturity of the insurance industry, but also other factors such as culture and history, may impact BMS design. Hence we introduce two non-economic variables that may influence BMS.

\section{Uncertainty avoidance}

In a celebrated study, Hofstede ${ }^{15}$ analysed the answers of 117,000 cultural survey questionnaires collected within subsidiaries of a large multinational business organisation, in 66 countries. Four cultural dimensions of national culture emerged from the study:

- Power distance: measures how societies react to human inequality;

- Individualism: describes the relationship between the individual and the collectivity prevailing in a given culture;

- Masculinity: evaluates whether biological gender differences impact roles in social activities;

- Uncertainty avoidance: scores tolerance for uncertainty.

Different societies, and business organisations within societies, react differently to uncertainties about the future and the resulting anxiety and need for security. They try to cope with risk by introducing laws, rules, regulations, religion and technology. Uncertainty-avoiding societies promote employment stability, select managers on the

\footnotetext{
${ }^{15}$ Hofstede (2001).
} 
basis of seniority, are suspicious towards foreigners as managers, and rely excessively on external consultants. Uncertainty-avoiding individuals purchase more mineral water and fresh fruits, buy their cars new, avoid "do-it-yourself" large projects at home, and prefer skill and strategic games over games of chance.

There is some evidence that uncertainty avoidance impacts financial markets. De Mooij ${ }^{16}$ finds that individuals residing in high uncertainty avoidance countries invest less in stocks and more in goods. Kwok and Tadesse ${ }^{17}$ show that financial systems are more likely to be bank-based in high uncertainty avoidance countries, and market-based (relying on stockmarkets) in low uncertainty avoidance countries.

While the management concept of uncertainty avoidance is not identical to insurance researchers' notion of risk aversion, it is certainly correlated. It represents the best available international measure of attitudes towards risk across countries, and is used in our analysis to explore the possible impact of cultural attitudes in the toughness of BMS. High uncertainty avoidance countries are likely to have milder BMS because tough BMS means more risk in future premiums.

A high score on this measure characterises uncertainty-avoiding societies, such as Japan and Korea. China, Hong Kong and Singapore receive the lowest scores in Asia.

\section{Commonwealth countries}

While every country has its own specific legal rules, scholars broadly subdivide all legal systems of the world in two families. Civil Law systems originated with Roman Law and the Napoleonic Code, and were spread around the world by France through conquest, colonisation, cultural dominance and imitation. Common Law systems are based on British law, and are in force in the countries that were colonised or heavily influenced by the British. Seven of the 16 Asian countries under study are former British colonies, and are members of the Commonwealth of Nations. Their legal system is based on Common Law. The other countries use Civil Law. The classification used in this research is based on Reynolds and Flores. ${ }^{18}$ Out of the 16 Asian countries included in our database, eight use a Civil Law system.

The legal system in force in a country may impact the development of insurance, as it specifies the liabilities of those responsible of damage, and defines the business environment of insurance companies. ${ }^{19}$ For instance, the United States leads the world in per capita consumption of liability insurance. The American legal system may be a contributing factor, by encouraging Americans to over-consume property-liability insurance. $^{20}$

\footnotetext{
${ }^{16}$ De Mooij (1998).

${ }^{17}$ Kwok and Tadesse (2006).

${ }^{18}$ Reynolds and Flores (1998).

19 Browne et al. (2000).

${ }^{20}$ Syverud et al., 1994).
} 


\section{An index of insurance maturity}

Due to the fairly low number of observations and high correlations between some variables, to avoid possible multicollinearity problems we construct an Index of Insurance Maturity using principal components analysis based on our first four measures, the insurance industry-oriented variables: insurance density and penetration, market concentration, and number of actuaries (GDP and Political Risk Index will be used as alternative measures of insurance market maturity later in the analysis).

We do not need to limit our sample to Asian countries to construct our Insurance Maturity Index: a larger sample will improve the efficiency of the principal component analysis and improve the significance of explanatory variables. Furthermore, a larger sample will enable us to compare the insurance market maturity of Asia to markets in other continents. Therefore, we use worldwide data $(82 \text { countries })^{21}$ to construct the Insurance Maturity Index. The first principal component, providing an excellent summary of the four variables by explaining 66.95 per cent of the total variance, is our Index of Insurance Maturity. ${ }^{22}$ Table 2 presents the correlation coefficients between the first two factors and the four selected variables.

Where do Asian countries rank in the world? Table 3 presents the factor score of all 16 Asian countries, in decreasing order, and their worldwide rank.

Taiwan ranks highest among Asian countries on this Index. Taiwan has enjoyed an open, competitive market for many years, as 31 non-life insurance offices operated in the country in the colonial period. In 1995, restrictions on foreign investment in joint ventures were eliminated, and the market opened to insurers from all nationalities. Privatisation was fully completed in 2002 with the revocation of the Central Reinsurance Act. Competition is intense, as Taiwan is a closed market with little new business, and more capacity available than is required to support the needs of the domestic industry. Further examples of insurance maturity include a Residential Earthquake Insurance Pool and a Nuclear Pool. This open market has made Taiwan the $13^{\text {th }}$ largest market in the world, quite a performance given that its population is only 23 million. ${ }^{14}$ With 16.2 per cent, Taiwan ranks first in the world in overall insurance penetration, well ahead of the other mature Asian markets: South Korea $\left(5^{\text {th }}\right)$, Hong Kong $\left(6^{\text {th }}\right)$, Japan $\left(9^{\text {th }}\right)$ and Singapore $\left(17^{\text {th }}\right)$.

The average of the 16 Asian scores is -0.5149 . As worldwide scores have a mean of 0 and a STD of 1 , we reach a first conclusion:

Conclusion 1: Asia mostly ranks low on the Index of Maturity. Only five out of 16 Asian countries receive a positive score. The most mature Asian market, Taiwan, only ranks $20^{\text {th }}$. Six Asian countries rank in the bottom 12 .

\footnotetext{
${ }^{21}$ Swiss Re's density and penetration data was available for those 88 countries that registered premium volumes of at least US\$ $347 \mathrm{~m}$ in 2006 . Data for six of those countries was not available from the Axco International Fact Book, resulting in 82 countries included in our sample.

${ }^{22}$ The second component explains about 20.44 per cent of the variation and it is highly correlated with market concentration. It appears to be uncorrelated with insurance maturity.
} 
Table 2 Correlations between factors and variables

\begin{tabular}{lrr}
\hline Variable & Factor 1 & Factor 2 \\
\hline Herfindahl & -0.5293 & 0.8434 \\
Density & 0.9432 & 0.2309 \\
Penetration & 0.8812 & 0.0399 \\
Actuaries & 0.8554 & 0.2261 \\
\hline
\end{tabular}

Table 3 First factor scores

\begin{tabular}{|c|c|c|}
\hline Country & Index score & World rank \\
\hline Taiwan & 0.5675 & 20 \\
\hline Hong Kong & 0.4582 & 24 \\
\hline Japan & 0.1568 & 27 \\
\hline Korea & 0.0993 & 29 \\
\hline Singapore & 0.0827 & 30 \\
\hline Malaysia & -0.2483 & 40 \\
\hline Thailand & -0.4097 & 45 \\
\hline Kazakhstan & -0.7033 & 63 \\
\hline Indonesia & -0.7697 & 65 \\
\hline Philippines & -0.7870 & 66 \\
\hline Bangladesh & -0.9231 & 71 \\
\hline Pakistan & -0.9581 & 72 \\
\hline India & -1.0609 & 75 \\
\hline Sri Lanka & -1.1093 & 76 \\
\hline China & -1.2459 & 79 \\
\hline Vietnam & -1.3873 & 82 \\
\hline Asian average & -0.5149 & \\
\hline
\end{tabular}

\section{The influence of national culture and insurance maturity on BMS toughness}

\section{Summary statistics and empirical analysis design}

Table 4 presents summary statistics and correlation coefficients between CV and all variables.

Partly as the result of the low sample size, only one variable is significantly different from zero $(\alpha=5$ per cent) in Asia: Commonwealth. It may come as a surprise that Commonwealth comes up as the most influential variable on BMS design, and not insurance maturity or GDP. The 16 Asian countries have very different insurance markets. China, India and Vietnam are still highly regulated, as the market share of state insurance companies is higher than 45 per cent. Bangladesh and Pakistan are regulated, but allow limited foreign participation: the market share of state insurers is more than 10 per cent, and the share of foreign branches or companies is less than 10 per cent. Indonesia and Kazakhstan are regulated but open to foreign investment and/or participation. Japan, Korea, Sri Lanka, Taiwan and Thailand allow limited 


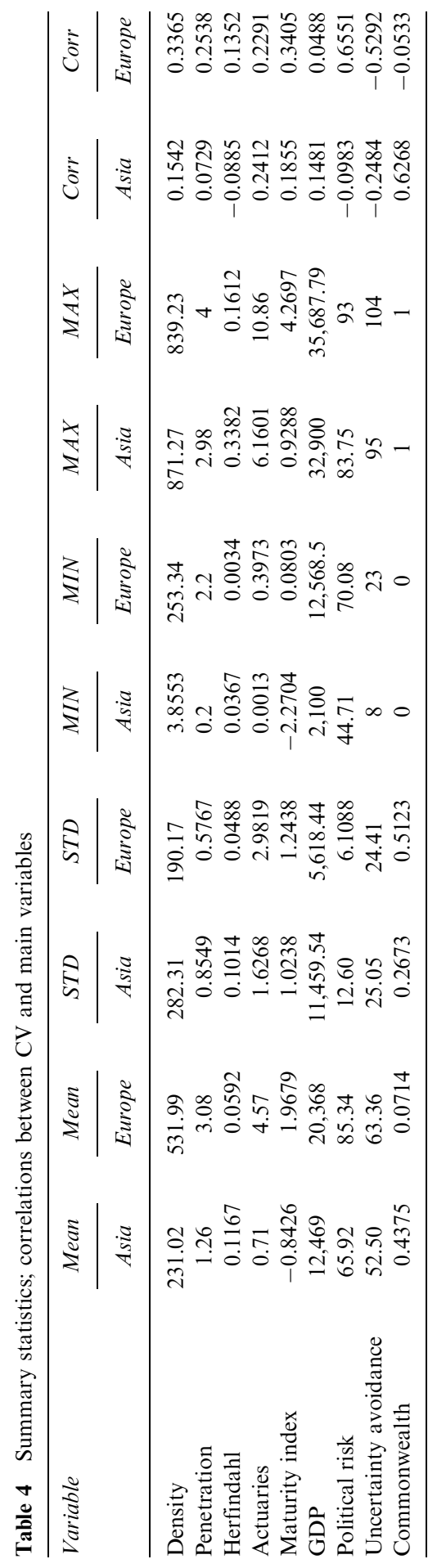


foreign participation. Hong Kong, Malaysia, Philippines and Singapore have totally opened their markets. It is then unexpected that a single factor-participation in the Commonwealth of Nations - drives the toughness of BMS.

We conjecture that there could be two possible explanations for this. The first is that, according to legal research, Common Law is more conducive to economic development, with the consequence that Commonwealth countries may implement more efficient and more severe BMS. The second explanation is that BMS were introduced much earlier in Britain than in Continental Europe; upon achieving independence, former British colonies had well-established BMS in place, while former colonies of Continental European powers had no BMS (or embryonic BMS) and had other priorities in developing their insurance markets than devising tough BMS. In the Discussion section, we discuss these two possible explanations in more detail.

In order to investigate whether the strong correlation between $\mathrm{CV}$ and Commonwealth is due to their legal system or a historical reason, we introduce an interaction variable (Insurance Maturity $\times$ Commonwealth) in our regression analyses. If the historical explanation is true (British BMS were in place at independence), we should find a stronger Commonwealth effect among countries with less mature insurance market. Advanced countries modify their BMS now and then to adapt to changing driving conditions, while developing countries do not consider BMS rating to be a crucial part of their insurance system. Consequently, we expect the poorer former colonies of Britain to have left their BMS mostly unchanged, while Britain's influence on BMS should have progressively dissipated in Asia's mature markets. On the other hand, if a Common Law system is the reason for the strong correlation, its impact will be similar for all countries, advanced or not, and we do not expect to find a significant effect on this interaction variable.

\section{Results of regression analyses for Asian countries}

In this section, regression analyses are presented to help us understand the factors driving the design of a BMS. First, we run a regression model with $\mathrm{CV}$ as dependent variable and the Insurance Maturity Index, Uncertainty Avoidance, Commonwealth, and the interaction term as explanatory variables (regression 1 in Table 5). Alternatively, we also run models with GDP and Political Risk Index, respectively, as economic development measures instead of Insurance Maturity Index (regressions 2 and 3 in Table 5). We do not include these three variables simultaneously due to their high correlations. As our dependent variable, $\mathrm{CV}$, cannot take negative values, we run Tobit models. ${ }^{23}$

The regression coefficients of Insurance Maturity Index, GDP and Political Risk, are all positive: the Lemaire and $\mathrm{Zi}$ conjecture that more mature insurance market have tougher BMS receives ample support. Noteworthy is the result that the main factor impacting the design of a BMS is the legal system: positive regression coefficients in all specifications imply that Commonwealth countries tend to use

\footnotetext{
${ }^{23}$ We also run the same model using OLS, and a model treating Kazakhstan and Philippines as missing countries, rather than countries with a $\mathrm{CV}$ equal to zero. Alternative regression models are presented in Appendix A.
} 
Table 5 Regression results: Asian countries

\begin{tabular}{|c|c|c|c|}
\hline \multirow[t]{2}{*}{ Regression variable } & (1) & (2) & (3) \\
\hline & Maturity index & $G D P$ & Political risk \\
\hline Commonwealth & $\begin{array}{l}0.0205 \\
(0.18)\end{array}$ & $\begin{array}{l}0.3157^{* * * *} \\
(3.50)\end{array}$ & $\begin{array}{l}0.2813 \\
(0.73)\end{array}$ \\
\hline Uncertainty avoidance & $\begin{array}{l}-0.0027 \\
(-1.37)\end{array}$ & $\begin{array}{l}-0.0027 \\
(-1.36)\end{array}$ & $\begin{array}{l}-0.0002 \\
(-0.12)\end{array}$ \\
\hline Maturity index & $\begin{array}{l}0.1032 * \\
(2.10)\end{array}$ & & \\
\hline GDP & & $\begin{array}{l}0.0101 * \\
(2.10)\end{array}$ & \\
\hline Political risk & & & $\begin{array}{l}0.0004 \\
(0.10)\end{array}$ \\
\hline Interaction & $\begin{array}{l}-0.1422 \\
(-1.74)\end{array}$ & $\begin{array}{l}-0.0142^{*} \\
(-1.87)\end{array}$ & $\begin{array}{l}-0.0014 \\
(-0.23)\end{array}$ \\
\hline Constant & $\begin{array}{l}0.3348 * * \\
(2.21)\end{array}$ & $\begin{array}{l}0.1214 \\
(1.24)\end{array}$ & $\begin{array}{l}0.0720 \\
(0.25)\end{array}$ \\
\hline Number of observation & 16 & 16 & 16 \\
\hline LR chi $^{2}$ & 11.88 & 12.02 & 7.79 \\
\hline Prob $>$ chi $^{2}$ & 0.0183 & 0.0172 & 0.0995 \\
\hline Joint test $F$-value for commonwealth and interaction & $6.23 * *$ & $6.61 * *$ & $3.73^{*}$ \\
\hline
\end{tabular}

Note: $t$-statistics are in parentheses. ${ }^{* * *}$ significant at 1 per cent, ${ }^{* *}$ significant at 5 per cent, ${ }^{*}$ significant at 10 per cent.

tougher BMS. The joint test $F$-statistic for Commonwealth and the interaction term shows significance in all models; the negative regression coefficient suggest that the impact of Commonwealth membership is weak in mature insurance markets, and mostly impacts poorer countries. This supports the historic hypothesis of the Commonwealth's impact on BMS.

Conclusion 2: As markets become more mature and policy-holders more sophisticated, countries adopt tougher BMS. BMS should evolve over time, to properly reflect changing economic conditions. Economic development leads to increased traffic, and a decrease in accident claim frequencies. Insurers should respond to these developments by enforcing tougher BMS, penalizing more claims at-fault, which would enable them to provide higher discounts to better drivers.

Conclusion 3: Common Law legal systems, in force in former British colonies, appear to be a major contributing force to BMS design, especially in poorer countries.

\section{Results of regression analyses for expanded data set}

In Table 5, the cultural variable, uncertainty avoidance, has the predicted sign, but is not significant. This may be due to the limited sample size. In order to achieve a better 
Table 6 Regression results: Expanded data set

\begin{tabular}{|c|c|c|c|c|c|}
\hline \multirow[t]{2}{*}{ Regression variable } & (1) & (2) & (3) & (4) & (5) \\
\hline & $\begin{array}{l}\text { Asia } \\
\text { only }\end{array}$ & $\begin{array}{c}\text { Europe } \\
\text { only }\end{array}$ & $\begin{array}{l}\text { Maturity } \\
\text { index }>0\end{array}$ & $\begin{array}{l}\text { Maturity } \\
\text { index }<0\end{array}$ & $\begin{array}{l}\text { Whole } \\
\text { sample }\end{array}$ \\
\hline Commonwealth & $\begin{array}{l}0.0205 \\
(0.18)\end{array}$ & $\begin{array}{l}-0.1373 \\
(-1.60)\end{array}$ & $\begin{array}{l}-0.1098^{*} \\
(-1.77)\end{array}$ & $\begin{array}{l}0.2578 * * * \\
(3.34)\end{array}$ & $\begin{array}{l}0.0974^{*} \\
(2.01)\end{array}$ \\
\hline Uncertainty avoidance & $\begin{array}{l}-0.0027 \\
(-1.37)\end{array}$ & $\begin{array}{l}-0.0023^{* *} \\
(-2.55)\end{array}$ & $\begin{array}{l}-0.0025^{* * *} \\
(-3.17)\end{array}$ & $\begin{array}{l}-0.0031 \\
(-1.22)\end{array}$ & $\begin{array}{l}-0.0017^{*} \\
(-1.99)\end{array}$ \\
\hline Maturity index & $\begin{array}{l}0.1032 * \\
(2.10)\end{array}$ & $\begin{array}{l}0.0259 \\
(1.43)\end{array}$ & $\begin{array}{l}0.0256 \\
(1.61)\end{array}$ & $\begin{array}{l}0.0109 \\
(0.15)\end{array}$ & $\begin{array}{l}0.0478 * * \\
(2.61)\end{array}$ \\
\hline Interaction & $\begin{array}{l}-0.1422 \\
(-1.74)\end{array}$ & & & & $\begin{array}{l}-0.0709 * * \\
(-2.95)\end{array}$ \\
\hline Asia & & & $\begin{array}{l}0.0159 \\
(0.32)\end{array}$ & & $\begin{array}{l}-0.0515 \\
(-0.83)\end{array}$ \\
\hline Constant & $\begin{array}{l}0.3348 * * \\
(2.21)\end{array}$ & $\begin{array}{l}0.3661 * * * \\
(4.80)\end{array}$ & $\begin{array}{l}0.3760 * * * \\
(5.71)\end{array}$ & $\begin{array}{l}0.1978 \\
(1.01)\end{array}$ & $\begin{array}{l}0.2831^{* * *} \\
(4.24)\end{array}$ \\
\hline Number of obs & 16 & 14 & 19 & 11 & 30 \\
\hline LR chi $^{2}$ & 11.88 & 7.72 & 11.32 & 9.29 & 21.07 \\
\hline Prob $>$ chi $^{2}$ & 0.0183 & 0.0522 & 0.0232 & 0.0257 & 0.0008 \\
\hline $\begin{array}{l}\text { Joint test } F \text {-value for } \\
\text { commonwealth } \\
\text { and interaction }\end{array}$ & $6.23 * *$ & N.A. & N.A. & N.A. & $7.37 * * *$ \\
\hline
\end{tabular}

Note: $t$-statistics are in parentheses. $* * *$ significant at 1 per cent, $* *$ significant at 5 per cent, ${ }^{*}$ significant at 10 per cent.

significance of variables, we pool our Asian data with the European data from Lemaire and $\mathrm{Zi}^{1}$. So, in this section, our models incorporate 16 Asian BMS in force in 2008, and the 14 European BMS in force in $1992 .^{24}$

We understand that there could be systematic differences between Asia and Europe (continent effect), as well as between 2008 and 1992 (year effect). However, since all 2008 data is from Asian countries and all 1992 data is from European countries, a single dummy variable is sufficient to capture both continent and year effects. With the inclusion of this dummy variable, we are able to control for the systematic differences between Europe in 1992 and Asia in 2008, if any. This enables us to pool the two data sets and enhance the explanatory power of other variables of interest.

With the expanded data set, we first run a regression with only European countries. Summary statistics for European countries are presented in Table 4. Regression results are shown in column (2) of Table 6, with column (1) restating results from the Asian regression for comparative purposes. As the U.K. is the only Commonwealth country in Europe, no interaction term is introduced. Results show that regression coefficients

\footnotetext{
${ }^{24}$ Nearly all European countries used national BMS in the 1990s. Since freedom rating was introduced in the European Union in 2002, companies are now free to design their own BMS, and few countries have a national system. Consequently, we use 1992 BMS for Europe, using European 1992 data for all variables.
} 
$\mathrm{S} 20$

of Asian and European countries are somewhat different. First, Commonwealth is not an important factor in Europe; even the sign of the Commonwealth variable is different in the two models. Second, while the regression coefficients for uncertainty avoidance in the Asian and European models are similar, the variable is only statistically significant in Europe. That is, countries with higher uncertainty avoidance have significantly milder BMS in Europe.

The different results for Asia and Europe may simply be due to the fact that European markets are generally more mature. To explore this possibility, we run a regression for countries with a positive Maturity Index (regression 3, Table 6). This amounts to adding five Asian countries (Hong Kong, Japan, South Korea, Singapore and Taiwan) to the European group. Regression coefficients hardly change and become more significant, adding robustness to our conclusions. The dummy variable Asia, added to capture the year and continent effect, has no significant effect. Uncertainty avoidance remains a highly significant explanatory variable, further demonstrating the importance of cultural aspects in BMS design in mature markets.

Another regression for countries with a negative Maturity Index (regression 4, Table 6) markets further demonstrates the importance of Commonwealth for poorer countries, supporting the historic influence hypothesis that poor Commonwealth countries inherited a BMS that they hardly changed since independence.

Finally, another regression for all 30 countries is presented (regression 5, Table 6), that includes an interaction term (Commonwealth $\times$ Maturity Index) to capture the differential effect of Commonwealth on more and less mature markets. Results are consistent with previous findings: BMS toughness is associated with Commonwealth, uncertainty avoidance and insurance market maturity. A strong Commonwealth effect only appears among less mature markets, further supporting the historic influence hypothesis.

\section{Discussion}

The main conclusion of the previous section is that-perhaps surprisingly - a legal system based on Common Law, characteristic of Commonwealth countries, is a main contributor to the enactment of tougher BMS. We provide two possible explanations, based on insurance history and characteristics of legal systems. Our regression analyses support the historical explanation.

\section{Possible superiority of common law legal systems}

In Civil Law countries, legislation is the primary source of law. Civil Law is based on a code that specifies main principles, and on new statutes passed by legislature to amend the existing code. Courts base their decisions on the provisions of codes and statutes. Judicial precedent is given little weight. By contrast, individual cases are the primary source of Common Law. Laws develop through court decisions rather than through statutes. Judges create and refine the law: when a new situation arises, judges have the authority to make law, and so create a precedent that binds future decisions. Proponents of Civil Law claim that systematic codification is conducive to certainty and unity. Opponents fear that codification results in the ossification of the law. They 
claim that Common Law is more adaptable to new trends because it responds, case by case, to the changing needs of society; judges progressively reinterpret the law that evolves through a series of progressive steps.

Some legal research claims that Common Law is more conducive to economic development than Civil Law. La Porta et al. ${ }^{25}$ uses regression analysis to show that Common Law countries generally have higher law enforcement quality and stronger legal protections of creditors and investors. Min $^{26}$ argues that Common Law's reliance on judicial opinion may contribute to commercial growth. Precedents provide reasonable guidance on issues and more certainty of outcome in case of a dispute, so parties can predict whether a proposed action is likely to be lawful. By contrast, in Civil Law countries, consistency is not guaranteed, judges must rule anew on each issue; parties cannot rely on a large body of precedents. As a result Common Law countries adapt more rapidly to changing conditions and new opportunities. ${ }^{27}$

Insurance may be a textbook example of the ossification of laws in Civil Law countries and adaptability in Common Law systems. Until the 2002 rating freedom mandated by EU directives, insurers in most Continental European countries operated under a system of compulsory premiums approved by governmental authorities, with little room for creativity and competition. By contrast, British insurers have always enjoyed full rating freedom and little supervision from the Department of Trade and Industry. ${ }^{28}$ British policy-holders have always been offered a considerable diversity of motor insurance products, with each insurer free to decide on its own rating structures and on premium relativities within these structures.

The creativity and adaptability allowed by Common Law systems is also evident in BMS design. Continental European insurers have tried to maintain uniform national BMS as long as possible after the 2002 laws. France and Luxembourg even won court cases allowing them to keep a common BMS for all companies. British insurers have taken advantage of the flexibility allowed by Common Law to offer different BMS; their policy-holders at one point were able to choose among more than 50 different sets of transition rules and premium levels. British insurers were also the first to introduce a "protection clause" in their BMS, allowing partial or total forgiveness of the first accident at-fault.

\section{Historical development of BMS}

In a summary of the development through time of BMS, Lemaire ${ }^{3}$ mentions that British insurers introduced simple merit-rating systems in auto insurance as early as the 1910s, while Continental European companies mostly developed their BMS in the 1960s, following early ASTIN work (among others see Bichsel ${ }^{4}$, Bühlmann ${ }^{29}$ and Delaporte $^{30}$ ). Consequently, when they became independent after World War II, it is

\footnotetext{
${ }^{25}$ La Porta et al. (1998).

${ }^{26}$ Min (2006).

${ }^{27}$ Posner (2004).

28 Johnson (1985).

${ }^{29}$ Bühlmann (1964).

${ }^{30}$ Delaporte (1965).
} 
likely that Commonwealth countries had well-established, fairly severe BMS in place. Former colonies of Continental European countries, on the other hand, probably had no BMS in place at independence, given that their colonial power had yet to implement such systems (or only used embryonic systems).

Any change in BMS is usually strongly impacted by the existing situation: it is rarely the case that a completely new BMS is introduced, without any consideration to the previous system. More often than not, the change is evolutionary: stronger transition rules are enacted, super-discount bonus classes are added, a protection scheme is introduced. Consequently, it is probable that current BMS in some Asian Commonwealth countries do not deviate very much from the systems in force at independence. On the other hand, non-Commonwealth countries, that likely had no BMS in place at independence, needed to devise their own system. Since BMS design in these emerging insurance markets was not a high-priority task, it is not surprising that non-Commonwealth countries implemented fairly mild BMS.

Our results offer support to the historical explanation. Affluent countries, whether in Europe or Asia, belonging to the Commonwealth or not, regularly change their BMS to end up with a system that corresponds to their insurance maturity and cultural approach to insurance. Poorer countries do not consider BMS design as an important rating tool and keep their existing system; former British colonies inherited tough BMS that they hardly changed. Former colonies of Continental European powers did not inherit a BMS tradition, and implemented no BMS or a mild BMS. Examples abound: the Lemaire and $\mathrm{Zi}$ study mentions nine affluent countries that changed their BMS in the early 1990s. Japan changed its BMS three times in the 1980s, three times in the 1990s, and then again in 2004. In 1992, Singapore and Malaysia shared the same BMS; the richer of these two countries, Singapore, has changed its BMS since, while Malaysia has not.

\section{Acknowledgements}

This research was funded in whole by the Wharton-SMU Research Center at Singapore Management University. Many thanks to Axco and the many colleagues - too numerous to be cited individually — who helped us build the database for this project.

\section{References}

Albrecht, P. (1982) 'On some statistical methods connected with the mixed Poisson distribution', Scandinavian Actuarial Journal, 1-14.

AON (2008) 'Aon Insurance Risk Study: Risk Quantification in a Connected World', www.aon.com/ attachments/insurance-risk-study-aon-benfield.pdf.

Axco Insurance Markets Report (2007) Axco Insurance Markets Report, Taiwan: Non-Life (P\&C).

Bichsel, F. (1960) 'Une méthode pour calculer une ristourne adéquate pour années sans sinistres', $A S T I N$ Bulletin 1: 106-112.

Browne, M.J., Chung, J.W. and Frees, E.W. (2000) 'International property-liability insurance consumption', Journal of Risk and Insurance 67(1): 73-90.

Bühlmann, H. (1964) 'Optimale Prämienstufensysteme', Mitteilungen der Vereinigung Schweizerischer Versicherungsmathematiker 64: 193-213. 
Bühlmann, H. and Gisler, A. (2005) A Course in Credibility Theory and its Applications, Berlin: SpringerVerlag.

Chui, A and Kwok, C. (2008) 'National culture and life insurance consumption', Journal of International Business Studies 39(1): 88-101.

De Mooij, M. (1998) 'Masculinity/feminity and consumer behaviour', in G. Hofstede and Associates Editors (eds.) Masculinity and Feminity, the Taboo Dimension of National Cultures, Thousand Oaks, CA: Sage Publications, pp. 55-73.

Delaporte, P. (1965) 'Tarification du risque individuel d'accidents d'automobiles par la prime modelée sur le risque', ASTIN Bulletin 3: 251-271.

Denuit, M. (1997) 'A new distribution of Poisson-type for the number of claims', ASTIN Bulletin 27: $229-242$.

Derron, M. (1963) 'A theoretical study of the no-claim bonus problem', ASTIN Bulletin 3: 62-74.

Franckx, E. (1960) 'Théorie du bonus', ASTIN Bulletin 3: 113-122.

Gossiaux, A.-M. and Lemaire, J. (1981) 'Méthodes d'ajustement de distributions de sinistres', Mitteilungen der Vereinigung Schweizerischer Versicherungsmathematiker, 81: 87-95.

Hofstede, G. (2001) Culture's Consequences: Comparing Values, Behaviors, Institutions, and Organizations across Nations, 2nd edition, Thousand Oaks, CA: Sage Publications.

Johnson, P. (1985) 'United Kingdom', in J. Lemaire (ed.) Automobile Insurance: Actuarial Models, Boston, MA: Kluwer Publishing, pp. 22-28.

Kwok, C.Y. and Tadesse, S. (2006) 'National culture and financial systems', Journal of International Business Studies 37(2): 227-247.

La Porta, R., Lopez-de-Silanes, F., Schleifer, A. and Vishny, R.W. (1998) 'Law and finance', Journal of Political Economy 106(6): 1113-1155.

Lemaire, J. (2004) 'Bonus-malus systems', in J. Teugels and B. Sundt (eds.) Encyclopedia of Actuarial Science, Vol. 1, Chichester, West Sussex, UK: John Wiley and Sons, pp. 184-191.

Lemaire, J. and Zi, H. (1994) 'A comparative analysis of 30 bonus-malus systems', ASTIN Bulletin 24: 287-309.

Min, Y.T. (2006) A Note on Some Differences in English Law, New York Law, and Singapore Law, Singapore: Singapore Academy of Law.

Posner, R. (2004) 'Law and economics in common-law, civil-law, and developing nations', Ratio Juris 17 : 66-79.

Reynolds, T.H. and Flores, A.A. (1998) Foreign Law: Current Sources of Codes and Basic Legislation in Jurisdictions of the World, Littleton, CO: Rothman.

Swiss Reinsurance Company (2006) 'World insurance in 2005: Moderate premium growth, attractive profitability', Sigma 5: 1-40.

Syverud, K.D., Bovbjerg, R.R., Pottier, S.W. and Will, R.W. (1994) 'On the demand for liability insurance: Comments', Texas Law Review 72: 1629-1702.

Willmot, G. (1986) 'Mixed compound Poisson distributions', ASTIN Bulletin 16-S: 59-79.

\section{About the Authors}

Sojung Carol Park is an Assistant Professor of Finance at California State University, Fullerton. She received her BA and MS in Industrial Engineering from Seoul National University and $\mathrm{PhD}$ degree in Risk Management and Insurance from the Wharton School, University of Pennsylvania in 2009. Her current research interests focus on the areas of cultural effect on insurance market, risk management in insurance industry, securitised bonds, insurance company rating and market discipline, and insurance economics. She is an advisor for Gamma lota Sigma, the insurance student association, at CSUF.

Jean Lemaire is the Harry J. Loman Professor of Insurance and Actuarial Science and Director of the Actuarial Science program at the Wharton School of the University of 
Pennsylvania. He obtained his PhD in Applied Mathematics at the Free University of Brussels. An Honorary Chairman of ASTIN, he is mostly known for his books on Bonus-Malus Systems in Automobile Insurance, voted insurance book-of-the-year both in Europe and the USA.

Choong Tze Chua is an assistant professor of finance at Singapore Management University. He obtained his PhD from The Wharton School at the University of Pennsylvania. His research interest includes yield curve models, empirical asset pricing and insurance. His work have appeared in publications such as Review of Financial Studies, Journal of Financial and Quantitative Analysis, Journal of Banking and Finance, Journal of Financial Research and Journal of Fixed Income.

\section{Appendix A}

\section{Alternate models}

In this section we provide two alternative regression models: a model that excludes the two countries (Kazakhstan and Philippines) with no BMS, and an OLS regression using the robust error option in Stata. The results demonstrate the robustness of our conclusions. Countries with mature insurance market and low uncertainty avoidance, and Commonwealth countries, have tougher BMS. The effect of Commonwealth is stronger in less developed markets (Table A1).

Table A1 Alternative models

\begin{tabular}{lcc}
\hline Variable & $(1)$ & $(2)$ \\
\cline { 2 - 3 } & Without Kazakhstan and Philippines & OLS model \\
\cline { 2 - 3 } Commonwealth & 0.0742 & 0.0901 \\
Uncertainty avoidance & $(1.57)$ & $(1.53)$ \\
& $-0.0015^{*}$ & $(-2.20)$ \\
Maturity index & $(-1.85)$ & $0.0455^{* * *}$ \\
(Maturity index $\times$ Commonwealth) & $0.0421^{* *}$ & $(2.39)$ \\
& $(2.40)$ & $-0.0668^{* * *}$ \\
Asia & $-0.0615^{* *}$ & $(-3.26)$ \\
Constant & $(-2.64)$ & -0.0437 \\
& -0.0319 & $(-0.61)$ \\
Number of obs & $(-0.54)$ & $0.2791^{* * *}$ \\
LR chi ${ }^{2}$ & $0.2852^{* * *}$ & $(4.04)$ \\
Prob $>$ chi & $(4.39)$ & 30 \\
$R$-square & & 11.98
\end{tabular}

Note: $t$-statistics are in parentheses. $* * *$ significant at 1 per cent, $* *$ significant at 5 per cent, $*$ significant at 10 per cent. 


\section{Hofstede's other cultural variables}

Hofstede $^{15}$ provide four dimensions of national culture: individualism, uncertainty avoidance, power distance and masculinity. We only included uncertainty avoidance in our models to test the hypothesis that milder BMS are preferred by high uncertainty avoidance consumers, other things being equal. Indeed uncertainty avoidance is the only measure introduced by Hofstede that relates to an insurance concern: risk aversion. However, it is possible that other cultural variables may influence BMS design, and omitted variable may bias estimates. Therefore, we run the same regression models including Hofstede's other cultural measures.

Table A2 demonstrates the robustness of our conclusions: the other cultural variables are all statistically insignificant in all models; regression coefficients hardly change after inclusion of other cultural variables. Therefore we conclude that only the uncertainty avoidance measure is associated with the toughness of bonus-malus system. Omitting other cultural variables does not cause bias.

Table A2 Regression results with Hofstede's other cultural variables

\begin{tabular}{|c|c|c|c|c|}
\hline \multirow[t]{2}{*}{ Regression variable } & (1) & (2) & (3) & \multirow{2}{*}{$\frac{(4)}{U A \text { and } P D I}$} \\
\hline & $U A$ only & $U A$ and $I N D$ & $U A$ and $M A S$ & \\
\hline Commonwealth & $\begin{array}{l}0.0974 * \\
(2.01)\end{array}$ & $\begin{array}{l}0.1051^{* *} \\
(2.17)\end{array}$ & $\begin{array}{l}0.1072 * * \\
(2.16)\end{array}$ & $\begin{array}{l}0.1054^{* * *} \\
(2.12)\end{array}$ \\
\hline Uncertainty avoidance & $\begin{array}{l}-0.0017^{*} \\
(-1.99)\end{array}$ & $\begin{array}{l}-0.0018^{* *} \\
(-2.17)\end{array}$ & $\begin{array}{l}-0.0014 \\
(-1.61)\end{array}$ & $\begin{array}{l}-0.0015 \\
(-1.67)\end{array}$ \\
\hline Individualism & & $\begin{array}{l}-0.0015 \\
(-1.06)\end{array}$ & & \\
\hline Masculinity & & & $\begin{array}{l}-0.0008 \\
(-0.77)\end{array}$ & \\
\hline Power distance & & & & $\begin{array}{l}-0.0009 \\
(-0.66)\end{array}$ \\
\hline Maturity index & $\begin{array}{l}0.0478 * * \\
(2.61)\end{array}$ & $\begin{array}{l}0.0509 * * \\
(2.78)\end{array}$ & $\begin{array}{l}0.0499 * * \\
(2.72)\end{array}$ & $\begin{array}{l}0.0434^{* *} \\
(2.23)\end{array}$ \\
\hline (Maturity index $\times$ commonwealth) & $\begin{array}{l}-0.0709 * * \\
(-2.95)\end{array}$ & $\begin{array}{l}-0.0715^{* * *} \\
(-3.01)\end{array}$ & $\begin{array}{l}-0.0676^{* * *} \\
(-2.81)\end{array}$ & $\begin{array}{l}-0.0688^{* * *} * \\
(-2.85)\end{array}$ \\
\hline Asia & $\begin{array}{l}-0.0515 \\
(-0.83)\end{array}$ & $\begin{array}{l}-0.1105 \\
(-1.33)\end{array}$ & $\begin{array}{l}-0.0345 \\
(-0.53)\end{array}$ & $\begin{array}{l}-0.0349 \\
(-0.53)\end{array}$ \\
\hline Constant & $\begin{array}{l}0.2831^{* * * *} \\
(4.24)\end{array}$ & $\begin{array}{l}0.3897 * * * \\
(3.23)\end{array}$ & $\begin{array}{l}0.2941 * * * \\
(4.36)\end{array}$ & $\begin{array}{l}0.3179 * * * \\
(3.74)\end{array}$ \\
\hline Number of obs & 30 & 30 & 30 & 30 \\
\hline LR chi $^{2}$ & 21.07 & 22.18 & 21.65 & 21.51 \\
\hline Prob $>\mathrm{chi}^{2}$ & 0.0008 & 0.0011 & 0.0014 & 0.0015 \\
\hline
\end{tabular}

Note: $t$-statistics are in parentheses. $* * *$ significant at 1 per cent, $* *$ significant at 5 per cent, ${ }^{*}$ significant at 10 per cent. 


\section{Appendix B}

See Table B1.

Table B1 Summary description of all BMS ${ }^{\mathrm{a}}$

\begin{tabular}{|c|c|c|c|}
\hline Country & Levels & Claim-free year & Claim penalties \\
\hline Bangladesh & $\begin{array}{l}50,60,70,100,130,140 \\
150\end{array}$ & $\begin{array}{l}\text { To level } 70 \text { if in malus } \\
\text { zone; one-class discount } \\
\text { o.w. }\end{array}$ & $\begin{array}{l}\text { To level } 130 \text { with one claim, } 140 \\
\text { with two claims, } 150 \text { with three } \\
\text { claims }\end{array}$ \\
\hline China & $\begin{array}{l}70,80,90,100,110,120 \\
130\end{array}$ & $\begin{array}{l}\text { To level } 90 \text { if at } 100 \text { or } \\
\text { above; }-1 \text { in bonus zone }\end{array}$ & $\begin{array}{l}\text { Independent of current level; to } \\
\text { level } 100 \text { if one or two claims, } 110 \text { if } \\
\text { three claims, } 120 \text { if four claims, } 130 \\
\text { if five plus claims }\end{array}$ \\
\hline Hong Kong & $40,50,60,70,80,100$ & One-class discount & Three-class penalty with each claim \\
\hline India & $\begin{array}{l}35,50,65,80,100,110 \\
130,150\end{array}$ & One-class discount & $\begin{array}{l}\text { One-class penalty with any number } \\
\text { of claims }\end{array}$ \\
\hline Indonesia & $80,85,90,95,100$ & One-class discount & Back to level 100 with any claim \\
\hline Japan & $\begin{array}{l}40,40,40,42,42,45,45 \\
50,50,55,60,60,70,80 \\
90,90,100,120,130,160\end{array}$ & One-class discount & Three-class penalty with each claim \\
\hline Korea & $\begin{array}{l}40,45,50,60,70,80,90 \\
100,110,120,130,140 \\
150,160,170,180,190 \\
200\end{array}$ & $\begin{array}{l}\text { Discount given after } \\
\text { three consecutive claim- } \\
\text { free years; one-class } \\
\text { discount if at } 100 \text { or } \\
\text { below, to } 100 \text { o.w. }\end{array}$ & $\begin{array}{l}\text { Complicated system penalizing } \\
\text { accidents with points depending on } \\
\text { cost of accident, degree of injury, } \\
\text { and severity of traffic offense }\end{array}$ \\
\hline Malaysia & $45,55,61.68,70,75,100$ & One-class discount & Back to level 100 with any claim \\
\hline Pakistan & $\begin{array}{l}66.67,75,80,85,90 \\
100,110,120,130,140\end{array}$ & $\begin{array}{l}\text { One-class discount if at } \\
\text { level } 100 \text { or below; to } \\
\text { level } 100 \text { if in malus zone }\end{array}$ & $\begin{array}{l}\text { One claim: two-class penalty if in } \\
\text { bonus zone; to level } 100 \text { if at } 90 \text {; to } \\
110 \text { o.w. two claims: to } 90 \text { if in best } \\
\text { class; to } 100 \text { if in bonus zone; to } \\
120 \text { o.w. three claims: to } 100 \text { if in } \\
\text { bonus zone; to } 130 \text { o.w. four } \\
\text { claims: to } 100 \text { if in bonus zone; to } \\
140 \text { o.w. }\end{array}$ \\
\hline
\end{tabular}

Singapore $\quad 50,60,70,80,90,100 \quad$ One-class discount Three-class penalty with each claim

Sri Lanka $\quad 30,35,40,45,55,65,75$, One-class discount

Three-class penalty if at level 30 , 85,100

35 , or 40 ; to 100 o.w.

Taiwan

$40,60,80,100,120,140, \quad$ On the basis of total number of claims in past three years. Each 160, 180, 200, 220, 240, year without a claim: -1 point. One claim in past three years: 260 0 point; each claim thereafter: +1 point. Each negative point decreases the premium by $20 \%$, each positive point increases the premium by $20 \%$ 
Table B1 (continued)

\begin{tabular}{llll}
\hline Country & Levels & Claim-free year & Claim penalties \\
\hline Thailand & $\begin{array}{l}50,60,70,80,100,120, \\
130,140,150\end{array}$ & $\begin{array}{l}\text { One-class discount if } \\
\text { at } 100 \text { or below; to } \\
100 \text { o.w. }\end{array}$ & $\begin{array}{l}\text { First claim: varying, one- or two- } \\
\text { class discount if in bonus zone; no } \\
\text { change o.w. Second claim: varying, } \\
\text { generally one additional class } \\
\text { penalty }\end{array}$ \\
Vietnam & $80,85,90,100$ & One-class discount & Back to level 100 with any claim \\
\hline
\end{tabular}

${ }^{\mathrm{a}}$ For some complicated systems, this summary description is not sufficient to perform a Markov analysis. 